\title{
INTEGRATION AND INNOVATION ORIENT TO E-SOCIETY VOLUME 2
}




\section{IFIP - The International Federation for Information Processing}

IFIP was founded in 1960 under the auspices of UNESCO, following the First World Computer Congress held in Paris the previous year. An umbrella organization for societies working in information processing, IFIP's aim is two-fold: to support information processing within its member countries and to encourage technology transfer to developing nations. As its mission statement clearly states,

IFIP's mission is to be the leading, truly international, apolitical organization which encourages and assists in the development, exploitation and application of information technology for the benefit of all people.

IFIP is a non-profitmaking organization, run almost solely by 2500 volunteers. It operates through a number of technical committees, which organize events and publications. IFIP's events range from an international congress to local seminars, but the most important are:

- The IFIP World Computer Congress, held every second year;

- Open conferences;

- Working conferences.

The flagship event is the IFIP World Computer Congress, at which both invited and contributed papers are presented. Contributed papers are rigorously refereed and the rejection rate is high.

As with the Congress, participation in the open conferences is open to all and papers may be invited or submitted. Again, submitted papers are stringently refereed.

The working conferences are structured differently. They are usually run by a working group and attendance is small and by invitation only. Their purpose is to create an atmosphere conducive to innovation and development. Refereeing is less rigorous and papers are subjected to extensive group discussion.

Publications arising from IFIP events vary. The papers presented at the IFIP World Computer Congress and at open conferences are published as conference proceedings, while the results of the working conferences are often published as collections of selected and edited papers.

Any national society whose primary activity is in information may apply to become a full member of IFIP, although full membership is restricted to one society per country. Full members are entitled to vote at the annual General Assembly, National societies preferring a less committed involvement may apply for associate or corresponding membership. Associate members enjoy the same benefits as full members, but without voting rights. Corresponding members are not represented in IFIP bodies. Affiliated membership is open to non-national societies, and individual and honorary membership schemes are also offered. 


\section{INTEGRATION AND INNOVATION ORIENT TO E-SOCIETY VOLUME 2}

Seventh IFIP International Conference on e-Business, e-Services, and e-Society (I3E2007), October 10-12, Wuhan, China

Edited by

Weijun Wang

HuaZhong Normal University, China

Yanhui Li

HuaZhong Normal University, China

Zhao Duan

HuaZhong Normal University, China

Li Yan

HuaZhong Normal University, China

Hongxiu Li

Turku School of Economics, Finland

Xiaoxi Yang

HuaZhong Normal University, China

\section{Springer}


Library of Congress Control Number: 2007

\section{Integration and Innovation Orient to E-Society, Volume 2}

Edited by W. Wang, Y. Li, Z. Duan, L. Yan, H. Li, and X. Yang

p. cm. (IFIP International Federation for Information Processing, a Springer Series in Computer Science)

ISSN: 1571-5736 / 1861-2288 (Internet)

ISBN: 978-0-387-75493-2

eISBN: $978-0-387-75494-9$

Printed on acid-free paper

Copyright $(2007$ by IFIP International Federation for Information Processing.

All rights reserved. This work may not be translated or copied in whole or in part without the written permission of the publisher (Springer Science+Business Media, LLC, 233 Spring Street, New York, NY 10013, USA), except for brief excerpts in connection with reviews or scholarly analysis. Use in connection with any form of information storage and retrieval, electronic adaptation, computer software, or by similar or dissimilar methodology now known or hereafter developed is forbidden.

The use in this publication of trade names, trademarks, service marks and similar terms, even if they are not identified as such, is not to be taken as an expression of opinion as to whether or not they are subject to proprietary rights.

Printed in the United States of America.

987654321

springer.com 


\section{Table of Contents}

\section{Volume 2}

\section{Conference Chair's Message}

\section{Organizing Committee}

\section{Program Committee}

\section{External Reviewers}

\section{e-Service Track}

Measuring the Performance of $G 2 G$ Services in Iran

Behrouz Zarei and Maryam Safdari

The Study on the Architecture of Public knowledge Service Platform Based on 9 Collaborative Innovation

Changping $\mathrm{Hu}$, Min Zhang and Fei Xiang

Wiki-based Knowledge Sharing in a Knowledge-Intensive Organization

Changping Hu, Yang Zhao and Xueqin Zhao

Web 2.0 Applications in China

Chen Liu and Dongsheng Zhai

On the Standardization of Semantic Web Services-based Network Monitoring Operations Chenling Zhao, Ziheng Liu and Yanfeng Wang

Antecedents for Building Trust in Professional e-Services

Dieter Fink

Service-Oriented Software Testing Platform

Fagui Liu and Chunwei Luo

Research on Externalization of Tacit Knowledge Based on Web2.0

Gang Li and Kun Lu

Application of Electronic Business in Safe Accident Prevention and Control on Coalface

Guozhi Lu, Jianqquan Tang, Chunhui Yao and Lei Yang

Fulfillment of HTTP Authentication Based on Alcatel OmniSwitch 9700

Hefu Liu 
A Concept Model of Public Medical Service System Based-on Cell Phone Mobile 88 Platform

Hongiao Fu and Yue Zhao

An Integrated Model in E-Government Based on Semantic Web, Web Service and 96 Intelligent Agent

Hongtao Zhu and Fangli Su

Electronic Commerce in Tourism in China: B2B or B2C?

Hongxiu Li and Reima Suomi

Customer's Perception and Intentions on Online Travel Service Delivery: An Empirical 113 Study in China

Hongxiu Li and Reima Suomi

Research on the Impetus Mechanism of Insitutional Repositories

Jun Deng and Qiang Bi

Study on Influencing Factor Analysis and Application of Consumer Mobile Commerce Acceptance

Li Gaoguang and Lv Tingjie

The Role of Post-adoption Phase Trust in B2C e-Service Loyalty: Towards a More Comprehensive Picture

Matti Mäntymäki

Open Access: How Is Scholarly Information Service System Going?

Nanqiang Xia and Yaokun Zhang

Analysis and Modelling of Willingness to Receive Reward for Relay in Ad Hoc Networks Naoyuki Karasawa, Kyoko Yamori, Kenji Donkai and Yoshiaki Tanaka

A Keyword Extraction Based Model for Web Advertisement

Ning Zhou. Jiaxin Wu and Shaolong Zhang

Study on Personalized Recommendation Model of Internet Advertisement

Ning Zhou, Yongyue Chen and Huiping Zhang

An Analysis on Modes of Scientific and Technological Information Integration Services in

Ping Wang, Weidong Zhang, Ye Yuan and Xueyan Song 
Ricardo Costa, Paulo Novais, José Machado, Carlos Alberto and José Neves

An Investigation and Analysis of Web Services in Major Subject Based Information Gateways in the World

Ruhua Huang and Chang Liu

Design of Web-based Management Information System for Academic Degree \& Graduate

Education

Rui Duan and Mingsheng Zhang

A Process Model of Partnership Evolution Around New IT Initiatives

Timo Kestilä, Hannu Salmela, Lauri Salmivalli and Annukka Vahtera

Design of a Web2.0-based Knowledge Management Platform

Weijun Wang. Rui Xiong and Jing Sun

AN Access Control Model of Workflow System Integrating RBAC and TBAC

Xiangnin Zhou and Zhaolong Wang

Study on 7echnological Innovation Risk of China's e-Services

Xiaobin Lu

Research of Default Rules Mining Model based on Reduced Lattice

Xinyuan Lu, Huili Zhang and Jinlong Zhang

WSDRI-based Semantic Web Service Discovery Framework

$\mathrm{Xu}$ Sun, YanLi Xu and MingRong Mao

Virtual Team Governance: Addressing the Governance Mechanisms and Virual Team

Performance

YiHong Zhan, Yu Bai and Ziheng Liu

Government Information Access Guiding for E-Government

Yikun Xia and Cui Huang

An Algorithm for Semantic Web Services Composition Based on Output and Input Matching

Ying $\mathrm{Li}$ and Baotian Dong

Ecological Analysis on Information Systems in Web2.0 Era

Ying Liu. Shuren Zhang and Meiqi Fang 
Yue Ming and Zhenjiang Miao

The Agent of Extracting Internet Information with Lead Order

Zan Mo, Chuliang Huang and Aijun Liu

Governmental Information Resources Management Base on metadata

Zhenlong Li and Xiaoming Zhao

Web Services Composition based on Domain Ontology and Discrete Particle Swarm

Opimization

Zhenwu Wang and Ming Chen

\section{e-Society Track}

Personal Knowledge Management based on Social Software

Chengling Zhao, Jianxia Cao and Xinhua Guo

The Design And Implementing of Collaborative Learning On Internet Curriculum

Development

Chengling Zhao and Li Lin

eGovGrid: A Service-Grid-Based Framework for E-Government Interoperability

Dongju Yang, Yanbo Han and Jinhua Xiong

Information Specificity Vulnerability: Comparison of Medication Information Flows in

Different Health Care Units

Eeva Aarnio and Reetta Raitoharju

Service quality of Early Childhood Education web portals in Finnish municipalities

Eija Koskivaara and Päivi Pihlaja

Exploring the Intelligent and Collaborative control for E-Government System

Fangli Su and Hongtao Zhu

Evaluating the E-government Based on BSC

Jianjun Cheng, Sencheng Cheng and Meiju Yang

A New Multi-Agent Approach to Adaptive E-Education 
A Research on Issues Related to RFID Security and Privacy

Jongki Kim, Chao Yang and Jinhwan Jeon

Business Models of E-Government---Research on Dynamic E-Government Based on

Web Services

Li Yan and Jiumin Yang

Education for Digitization: A Case Study on Sharing E-Information Resources in

University Library

Lihong Zhu

Role-bosed Administration of User-role Assignment and Its Oracle Implementation

Lilong Han, Qingtan Liu and Zongkai Yang

An Empirical Analysis of the Determinants of International Digital Divide

Liu Yun

Intergration of E-education and Knowledge Management

Liyong Wan, Chengling Zhao and Wei Guo

Spontanous Group Learning in Ambient Learning Environments

Markus Bick, Achim Jughardt, Jan M. Pawlowski and Patrick Veith

Roadmapping Future eGovernment Research: Government's Role and Responsibilities in the Virtual

Melanie Bicking

An E-education Framework based on Semantic Web Agents

Ming Dong and Rong Rong

A Framework for Web Usage Mining in Electronic Government

Ping Zhou and Zhongjian Le

A Theoretical Approach to Information Needs Across Different Healthcare Stakeholders Reetta Raitoharju and Eeva Aarnio

The Moderating Effect of Leader-member Exchange on the Job Insecurity- 505 Organizational Commitment Relationship

Sanman Hu and Mingqian Liu

Trust-based Access Control in Virtual Learning Community

Shujuan Wang and Qingtang Liu 
One Continuous Auditing Practice in China: Data-oriented Online Auditing(DOOA)

Wei Chen, Jincheng Zhang and Yuquan Jiang

Research on the Status Quo and System Architecture of the Web Information Resource

Evaluation

Wei Xu, Ji Liu and Xiangxing Shen

Citizen Engagement: Driving Force of E-Society Development

Xiaolin Qiu

The Personal Digital Library (PDL)-based e-learning: Using the PDL as an e-learning support tool

Xiaozhao Deng and Jianhai Ruan

Research on Methods of Processing Transit IC Card Information and Constructing

Transit OD Matrix

Xiuhua Han, Jin Li and Han Peng

Research on Implementation of E-Government Integrated Information Services

Xuedong Wang. Xianli Shang and Kun Fan

The E-learning System Used in the Civil Servants' Job-training

Rui Yang and Jianhai Ruan

Evaluate E-loyalty of Sale Website: a Fuzzy Mathematics Method

Ying Yi, Zhenyu Liu and Yingzi Xiong

CSPMS Supported by Information Technology

Zhang Hudan and Wu Heng

An Exploratory Discuss of New Ways for Competitive Intelligence on WEB2.O

Zhonghua Deng and Ling Luo

Erratum 


\section{CONFERENCE CHAIR'S MESSAGE}

This volume contains the papers presented at I3E2007, the seventh IFIP International Conference on e-Business/Commerce, e-Services and e-Society, which was held in Wuhan from 10-12 October 2007. The conference was sponsored by IFIP TC6/WG6.11 in co-operation with TC8, TC9, TC11, and TC6/WG 6.4.

The scope of six past I3E conferences was on e-Commerce, e-Business, and e-Government. It is changed to "e-Business, e-Services and e-Society" this time, which is not only a diction modification, but also represents the upcoming trends of integration and innovation in the growing areas of e-Business/Commerce, e-Services and e-Society. Modern Service Science based on e-Services is developing as a discipline in all over the world, which would undoubtedly improve the research and application of e-Commerce and e-Society. It really shows the integration and innovation of multidisciplinary research and application in e-Business/Commerce, e-Learning, e-Tourism, e-Government, e-Health, e-Payment, etc. All of these construct the base and bricks of the e-Society.

A total of 460 papers were submitted and 149 papers were accepted through double-blind reviewing, the submissions came from 20 different countries, and it is the first time for I3E to attract big attentions of so many Chinese scholars. We believe more and more Chinese authors will participate in the future activities of I3E.

I would like to express my sincere thanks to the many people that made this volume and the I3E2007 conference in Wuhan possible. The first thank you goes to Reima Suomi, co-chair of the IFIP WG6.11 and Executive Liason, who visited my university in 2005, encouraged me to attend the 13E2006 conference and trusts us to hold the 13E2007 in Wuhan. He has spent much time to discuss issues with us and answer our detailed questions on how to organize the conference. The next goes to Winfried Lamersdorf and Wojciech Cellary, co-chairs of the IFIP WG6.11. They have put forward many good suggestions to our team in preparing for the conference and this book. The third goes to Lefkada Papacharalambous and Narciso Cerpa, program co-chairs. The detailed help was always available from them. And total reviewers have paid great contribution for improving the quality of the already high-quality submitted papers. This conference would not have been possible without your huge support. Thank you very much, all of you.

I also would like to thank my leaders and several colleagues in HuaZhong Normal University. Our president, Ming Ma, vice-president, Zhongkai Yang and Dean, Xuedong Wang pay hight attention to this conference as a core academic activity in the university's and our department's portfolio. Dr.Yanhui Li, Zhao Duan and Li Yan have spent much time and paid much contribution works to edit book and perpare the conference. Our staff Yangai Cai, Tian Jie, Xiaoli Chi and postgraduated students Xiaoxi Yang and Jing Sun took care of the administration of the conference.

Special thanks go to our support institutes: Ministry of Education of People's Republic of China, Ministry of Commerce of People's Republic of China, Ministry of Information Industry of People's Republic of China, National Natural Science Foundation of China, Wang-Kuangchen 
Education Foundation and HuaZhong Normal University.

Finally, I want to thank all the contributors to this book and the conference, as well as the I3E2007 conference participants. Because the quality and success of the IFIP I3E2007 was based on the sound work of all the committee members, reviewers and participants.

Weijun Wang

13E2007 Wuhan Conference Chair 


\title{
Organizing Committee
}

\author{
Honorary General Chair
}

Ming Ma, Huazhong Normal University, Wuhan, China

\section{General Chair}

Zongkai Yang, Huazhong Normal University, Wuhan, China

Xuedong Wang, Huazhong Normal University, Wuhan, China

\section{Conference Chair}

Weijun Wang, Huazhong Normal University, Wuhan, China

\section{Program Co-Chairs}

Narciso Cerpa, University of Talca, Chile

Lefkada Papacharalambous, TEL of Halkida, Greece

\section{Liaison Chairs:}

Executive Liason: Reima Suomi, Turku School of Economics, Finland Europe: Volker Tschammer, FhG FOKUS, Germany

North America: Ranjan Kini, Indiana University Northwest, USA

South America: Manuel J.Mendes, Unisantos, Brazil

Asia-Pacific: Katina Michael, University of Wollongong, Australia

\section{Members of Organizing Committee}

Zhihao Chen, Zhongnan University of Economics and Law, China Weiguo Deng, South China Normal University, China

Xiaozhao Deng, Southwest University, China

Tingting He, Huazhong Normal University, China

Jinyi Hong, Ministry of Information Industry, China

Yisheng Lan, Shanghai University of Finance \& Economics, China

Hongxin Li, Dongbei University of Finance \& Economics, China

Jun Liu, Beijing Jiaotong University, China

Qingtang Liu, Huazhong Normal University, China

Tenghong Liu, Zhongnan University of Economics and Law, China

Yezheng Liu, HeFei University of Technology, China

Yong Liu, ZhengZhou Institute of Aeronautical Industry Managent, China

Zhenyu Liu, Xiamen University, China

Haiqun Ma, Heilongjiang University, China 
Shihua Ma, Huazhong University of Science \& Technology, China Weidong Meng, Chongqing University, China

Guihua Nie, Wuhan University of Technology, China

Zheng Qin, Tsinghua University, China

Yongzhong Sha, Lanzhou University, China

Xiaobai Sheng, Nanjing Audit University, China

Jinping Shi, Hubei University, China

Ling Song, China Electronic Commerce Association, China

Yuanfang Song, Central University of Finance and Economics, China

Baowen Sun, Renmin University of China, China

Binyong Tang,Donghua University, China

Xinpei Wang, Ministry of Commerce of the People's Republic of China, China

Yuefen Wang, Nanjing University of Science \& Technology, China

Yan Wu, Ministry of Education, China

Kang Xie, Sun Yat-Sen University, China

Yangqun Xie, Anhui University, China

Kuanhai Zhan, South West Univesity of Finance \& Economics, China

Ning Zhang, Beijing University, China

Liyi Zhang, Wuhan University, China

Bangwei Zhao, Xidian University, China

Chengling Zhao, Huazhong Normal University, China

Shuangyi Zheng South-Central University For Nationalities, China

\section{Local Arrangement Committee}

Yanhui Li, Huazhong Normal University, China, Chair

Zhao Duan, Huazhong Normal University, China

Li Yan, Huazhong Normal University, China

Xiaoxi Yang, Huazhong Normal University, China

Jing Sun, Huazhong Normal University, China 


\section{Program Committee}

Americo Nobre Amorim, Ufpe/FIR, Brazil

Melanie Bicking, Universität Koblenz-Landau, Germany

Regis Cabral, University of Umeå, Sweden

Wojciech Cellary, The Poznan University of Economics, Poland

Narciso Cerpa, Universidad de Talca, Chile

Deren Chen, Zhe Jiang University, China

Jin Chen, School of Business, China

Kok-Wai Chew, Multimedia University, Malaysia

Dirk Deschoolmeester, Universität Ghent, Belgium

Motohisa Funabashi, Hitachi, Japan

Rüdiger Grimm, Universität Koblenz-Landau, Germany

J. Felix Hampe, University of Koblenz-Landau, Germany

Farouk Kamoun, Campus Universitaire Manouba, Tunis

Dipak Khakhar, Lund University, Institute for Informatics, Sweden

Kos Koen, Parktown Business School of Entrepreneurship, South Africa

Dimitri Konstantas, University of Geneva, Switzerland

Irene Krebs, Brandenburgische Technische Universität, Cottbus, Germany

Winfried Lamersdorf, Universität Hamburg, Fachbereich Informatik, Germany

Gang Li, Wuhan University, China

Qi Li, Xi'an Jiaotong University, China

Yijun Li, Harbing Institute of Technology, China

Hongxiu Li, Turku School of Economics, Finland

Tingjie Lv, Beijing University of Posts and Telecommunications, China

Manuel Mendes, CENPRA and Uni Santos, Brazil

Zoran Milosevic, Deontik, Australia

Harri Oinas-Kukkonen, University of Oulu, Finland

Lefkada Papacharalambous, TEI of Halkida, Greece

Spyridon Papastergiou, University of Pireus, Greece

Despina Polemi, University of Pireaus, Greece

Kai Rannenberg, T-Mobile Stiftungsprofessur für m-Commerce, Frankfurt, Germany

Reinhard Riedl, Universitat Zürich, Switzerland

Santosh Shrivastava, Newcastle University, UK

Katarina Stanoevska-Slabeva, Universität St. Gallen, Switzerland

Reima Suomi, Turku School of Economics, Finland

Paula Swatman, University of South Australia, Australia

Roland Traunmüller, Universität Linz, Austria

Aphrodite Tsalgatidou, NTUA Athen, Greece

Hans Weigand, Tilburg University, Netherlands

Rolf T. Wigand, University of Arkansas at Little Rock, USA

Maria Wimmer, Universität Koblenz-Landau, Germany

Kyoko Yamori, Waseda University, Japan

Deli Yang, DaLian University of Technology, China 
Shanlin Yang, HeFei University of Technology, China

Jinglong Zhang, Huazhong University of Technology and Sciences, China

Jing Zhao, China University of Geosciences, China

Daoli Zhu, Fu Dan University, China

Hans-Dieter Zimmermann, Swiss Institute for Information Research, Switzerland 


\section{External Reviewers}

Eeva Aarni, Turku School of Economics, Finland

Melanie Bicking, The University of Koblenz-Landau, Germany

Yongjun Chen, GuangDong University of Business Studies, China

Cristina Chuva, Instituto Superior de Engenharia de Coimbra,Rua Pedro Nunes - Quinta da Nora,

COIMBRA, Portugal

Yufeng Duan, East China Normal University, China

Zimmermann Hans-Dieter, University of Applied Sciences HTW Chur, Switzerland

Jie Huang, Zhong Nan University of Economics and Law, China

Mingxue Huang, Wuhan University, China

Ruhua Huang, Wuhan University, China

Timo Kesti, Turku School of Economics, Finland

Eija Koskivaara, Turku School of Economics, Finland

Annette Lerine, Lawrence Technological University, USA

$\mathrm{Li} \mathrm{Li,} \mathrm{Nanjing} \mathrm{University} \mathrm{of} \mathrm{Science} \mathrm{\&} \mathrm{Technology,} \mathrm{China}$

Yichun Liu, GuangDong University of Business Studies, China

Wei Lu, Wuhan University, China

Xinyuan Lu, Huazhong Normal University, China

Matti Mäntymäki, Turku School of Economics, Finland

Xiaoming Meng, GuangDong University of Business Studies, China

Jin Nie, Wuhan University, China

Xiaolin Qiu, Wuhan University, China

Reetta Raitoharju, Turku School of Economics, Finland

Hannu Salmela, Turku School of Economics, Finland

Seppo Sirkemaa, Turku School of Economics, Finland

Lin Wang, Huazhong University of Science \& Technology, China

Lixin Xia, Huazhong Normal University, China

Lifang Xu, Wuhan University, China

Han Zhang, Georgia Institute of Technology,Atlanta, USA

Meijuan Zhang, Wuhan University, China

Xiaojuan Zhang, Wuhan University, China

The original version of this book was revised.

An erratum to this book can be found at DOI 10.1007/978-0-387-75494-9 73 